\title{
Progressive improvement of impaired visual acuity during the first year after transsphenoidal surgery for non-functioning pituitary macroadenoma
}

\author{
O. M. Dekkers · R. J. W. de Keizer · F. Roelfsema • \\ A. A. vd Klaauw - P. J. Honkoop - H. van Dulken • \\ J. W. A. Smit · J. A. Romijn · A. M. Pereira
}

Published online: 22 February 2007

(C) Springer Science+Business Media, LLC 2007

\begin{abstract}
Objective Improvement of visual field defects continues even years after the initial surgical treatment. Because this process of continuing improvement has not been documented for visual acuity, we audited our data to explore the pattern of recovery of visual acuity until 1 year after transsphenoidal surgery for nonfunctioning pituitary macroadenoma.

Design Retrospective follow-up study.

Patients Forty-three patients (mean age $56 \pm 14$ years), treated by transsphenoidal surgery for non-functioning pituitary macroadenoma, were included in this analysis.

Results Visual acuity improved significantly within 3 months after transsphenoidal surgery. The mean visual acuity increased from $0.65 \pm 0.37$ to $0.75 \pm 0.36$ $(P<0.01)$ (right eye), and from $0.60 \pm 0.32$ to $0.82 \pm 0.30(P<0.01)$ (left eye). Visual acuity was improved 1 year after transsphenoidal surgery compared to the 3 months postoperative values. The mean visual acuity increased from $0.75 \pm 0.36$ to $0.82 \pm 0.34$
\end{abstract}

O. M. Dekkers $(\square) \cdot$ F. Roelfsema .

A. A. vd Klaauw · P. J. Honkoop

J. W. A. Smit - J. A. Romijn - A. M. Pereira

Department of Endocrinology and Metabolic Diseases

C4-R, Leiden University Medical Center, P.O. Box 9600,

Leiden 2300 RC, The Netherlands

e-mail: o.m.dekkers@lumc.nl

\section{R. J. W. de Keizer}

Department of Ophtalmology, Leiden University Medical Center, Leiden, The Netherlands

H. van Dulken

Department of Neurosurgery, Leiden University Medical

Center, Leiden, The Netherlands
$(P<0.05) \quad$ (right eye), and from $0.82 \pm 0.30$ to $0.88 \pm 0.27(P<0.05)$ (left eye)

Conclusion Visual acuity improves progressively after surgical treatment for non-functioning pituitary macroadenomas, at least within the first year after transsphenoidal surgery.

Keywords Non-functioning macroadenoma . Surgery $\cdot$ Visual acuity

\section{Introduction}

Non-functioning pituitary macroadenomas (NFMA) are the most prevalent macroadenomas [1,2]. Patients with NFMA mainly present with decreased visual acuity, visual field defects and hypopituitarism, caused by mass effects of the tumor [3-5]. Transsphenoidal surgery is the treatment of choice, resulting in improvement of visual field defects in $75-100 \%$ of all patients [3-5]. Accordingly, visual acuity improves in the majority of patients [6-10], although visual field defects and visual acuity may worsen in a limited number of patients after surgery $[6,7,9,10]$.

The process of visual fields recovery starts directly after surgery and can already be documented on the second postoperative day [11]. This process of recovery is probably due to restoration of the velocity of conduction. However, improvement of visual field defects continues even years after the initial surgical treatment $[12,13]$. Although a reduced visual acuity is correlated with the extent of visual field defects [13, 14], postoperative changes in visual acuity do not parallel changes in visual fields in every case [6]. 
To our knowledge, the process of gradual visual improvement, has only been observed for visual field defects, but not for visual acuity [12]. This is, however, clinically relevant, since improvement of minor visual field defects can occur unnoticed, whereas improvement in visual acuity is almost invariably noticed, and can potentially overcome thresholds to previous impairments in daily life. We therefore audited our data to explore the pattern of recovery of visual acuity until 1 year after transsphenoidal surgery for nonfunctioning pituitary macroadenoma.

\section{Patients and methods}

\section{Patient selection}

Forty-three patients, mean age $56 \pm 14$ years, were included in this retrospective analysis. In order to obtain a homogenous cohort for assessment, the inclusion criteria were the following:

1. Compression of the optic chiasm on MRI by the pituitary tumor prior to surgery

2. Transsphenoidal surgery for non-functioning pituitary macroadenoma (diameter $>1 \mathrm{~cm}$ ) for decompression of the optic chiasm

3. Assessment of visual acuity at least once before surgery, and at least twice in the first year after surgery

4. The availability of two postsurgical MR scans, within a time frame of maximal 3 months of the ophtalmological assessments

We did not restrict the inclusion criteria to patients with visual field defects, but also included patients with clear compression of the optic chiasm without decreased visual function, for two reasons. First, we were interested in the pattern of change in visual function prior to surgery. Second, it is, at least theoretically, possible that in patients with compression of the optic chiasm, surgical treatment may decrease visual function. To overcome the potential effect of postoperative tumor-regrowth on visual outcome, patients were excluded from analysis if the 1 year post-operative scans revealed growth of residual tumor.

For complete assessment, we reviewed the patient records of all departments involved in the treatment of NFMA (Endocrinology, Neurosurgery, Ophthalmology). Endocrine (pituitary function) and ophthalmologic data (visual acuity and visual fields) were assessed before surgery, 3 and 12 months after surgery. An MRI was performed before surgery, 3-6 months and 12-15 months after surgery. Transsphenoidal surgery was performed by one of two neurosurgeons

Corrected visual acuity was determined by the Snellen chart $[15,16]$ and was scored for both eyes. Visual fields were assessed by Humphrey perimetry in all patients. Goldman perimetry was used as an additional tool to assess peripheral visual field defects. To increase the reliability of the visual field testing, assessment of the visual fields, and thereby also visual acuity, was preferably performed twice prior to surgical treatment. However, surgical treatment was not delayed due to double ophthalmologic testing in patients with severe impaired visual acuity.

\section{Definitions}

The diagnosis of non-functioning pituitary macroadenoma was based on two criteria: the presence of a pituitary macroadenoma $(>1 \mathrm{~cm})$ on MRI, and the absence of overproduction of any of the pituitary hormones. In all cases the diagnosis was histologically confirmed. Tumor size was classified according to Hardy [17]. Tumor extension was classified as suprasellar (Hardy $\mathrm{II}^{0}, \mathrm{~A}, \mathrm{~B}, \mathrm{C}^{\mathrm{C}}$ ) or parasellar/infrasellar

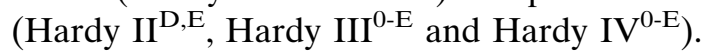

In all patients, visual acuity was scored on a scale between 0 and 1.25. Visual field defects were scored semi-quantitative and classified as mild, moderate or severe. Visual field defects were classified as mild, if there were peripheral defects in only one quadrant. Defects were classified as moderate if the upper quadrants were affected, whereas in combined upper and lower quadrant field defects, these were classified as severe.

Growth hormone $(\mathrm{GH})$ deficiency was defined as an insufficient rise in GH levels (absolute value $<3 \mu \mathrm{g} / \mathrm{l}$ ) after stimulation during an insulin tolerance test (ITT). When secondary amenorrhoea was present for more than 1 year premenopausal women were defined asLH/FSH deficient. Postmenopausal women were defined as LH/FSH deficient, when gonadotropin levels were below the normal postmenopausal range $(\mathrm{LH}<10 \mathrm{U} / 1, \mathrm{FSH}<30 \mathrm{U} / \mathrm{l})$. In men, LH/FSH deficiency was defined, as a testosterone level below the reference range $(8.0 \mathrm{nmol} / \mathrm{l})$. TSH deficiency was defined as a total or free T4 level below the reference range. ACTH deficiency was defined as a basal cortisol level at $8.00 \mathrm{AM}$ of $<0.12 \mu \mathrm{mol} / 1 \mathrm{and} /$ or an insufficient increase in cortisol levels (absolute value $<0.55 \mu \mathrm{mol} / \mathrm{l}$ ) after an ITT. 
Statistical analysis

The paired $t$-test was used for paired samples. SPSS software version 12.0 (SPSS Inc., Chicago, IL, USA) was used. A $P$-value of $<0.05$ was considered statistically significant.

\section{Results}

Preoperative patient characteristics (Table 1)

Forty-three patients, $51 \%$ male, were included in this study. Radiological imaging by MRI revealed a macroadenoma in all patients, with suprasellar extension in $100 \%$ and parasellar/infrasellar extension in $42 \%$ of cases. Hypopituitarism was present in $79 \%$ of all patients, and panhypopituitarism in $23 \%$.

Pre-operative assessment of visual function (Table 1)

Visual fields were normal in 4 patients. Transsphenoidal surgery in these patients was performed because compression of the optic chiasm was evident on the MR scan $(n=4)$. In these 4 patients visual acuity was at least 1.0 for both eyes. Of all patients with visual field defects $60 \%$ were classified as severe, $17 \%$ as moderate, and $14 \%$ as mild. Mean visual acuity was $0.65 \pm 0.37$ for the right eye, $0.60 \pm 0.32$ for the left eye.

Table 1 Patient characteristics before transsphenoidal surgery

\begin{tabular}{ll}
\hline Male/female & $22 / 21$ \\
Age (years \pm SD) & $56 \pm 14$ \\
Visual acuity & \\
Right eye (mean \pm SD) & \\
Left eye (mean \pm SD) & $0.65 \pm 0.37$ \\
Visual field defects & $0.60 \pm 0.32$ \\
Severe & \\
Moderate & $60 \%$ \\
Mild & $17 \%$ \\
None & $14 \%$ \\
Pituitary function & $9 \%$ \\
GH deficiency & \\
LH/FSH deficiency & $76 \%$ \\
ACTH deficiency & $69 \%$ \\
TSH deficiency & $43 \%$ \\
Panhypopituitarism & $36 \%$ \\
MRI characteristics & $23 \%$ \\
Suprasellar extension & \\
Infrasellar/parasellar extension & $100 \%$ \\
\hline
\end{tabular}

Visual acuity was assessed twice before surgery in 34 patients $(79 \%$ of total). The median time between the first and the second pre-surgical assessment was 4 weeks (range 1-45). No significant decrease in visual acuity was observed within this time period. The mean visual acuity for the two pre-surgical assessments was: $0.65 \pm 0.37$ vs. $0.66 \pm 0.38$ (right eye), and $0.60 \pm 0.32$ vs. $0.62 \pm 0.33$ (left eye). Moreover, no decrease in visual acuity was observed in patients $(n=13)$ with a time interval of $>8$ weeks between the first and the second pre-surgical assessment. In 4 of these patients there were no visual field defects.

\section{Surgical treatment}

All patients were treated by transsphenoidal surgery. Repeat surgery within 6 months after initial treatment was performed twice (large residual tumor mass $(n=1)$ and persisting liquor leakage $(n=1))$. Repeat surgery was performed by transcranial approach.

Transsphenoidal surgery was followed by radiotherapy in 10 patients in order to prevent recurrence. Patients received 40 Gy $(n=5)$ or 46 Gy $(n=5)$.

Three months postoperative assessment of visual function

After transsphenoidal operation in patients with preoperative visual field defects improvement was observed in $60 \%$ and normalization of the visual fields in $30 \%$. In 1 patient there was a slight increase in visual field defects.

Visual acuity improved significantly 3 months after transsphenoidal surgery (Fig. 1). The mean visual acuity increased from $0.65 \pm 0.37$ to $0.75 \pm 0.36$ $(P<0.01)$ (right eye), and from $0.60 \pm 0.32$ to $0.82 \pm 0.30(P<0.01)$ (left eye)

One-year postoperative assessment of visual function

One year after initial surgical therapy visual field defects showed continuous improvement in 36\% of patients, compared to early postoperative results. In $80 \%$ of them, this improvement was accompanied by continuous improvement of visual acuity.

In $56 \%$ of all patients $(n=24)$ visual acuity shows continuing improvement until 1 year after surgery. In 8 of them, this improvement was not accompanied by further improvement of visual field defects. Visual acuity was improved 1 year after transsphenoidal surgery compared to the 3 months postoperative values (Fig. 1). The mean visual acuity increased from 
Fig. 1 The pattern of improvement of visual acuity after transsphenoidal surgery for non-functioning pituitary macroadenomas $(n=43)$
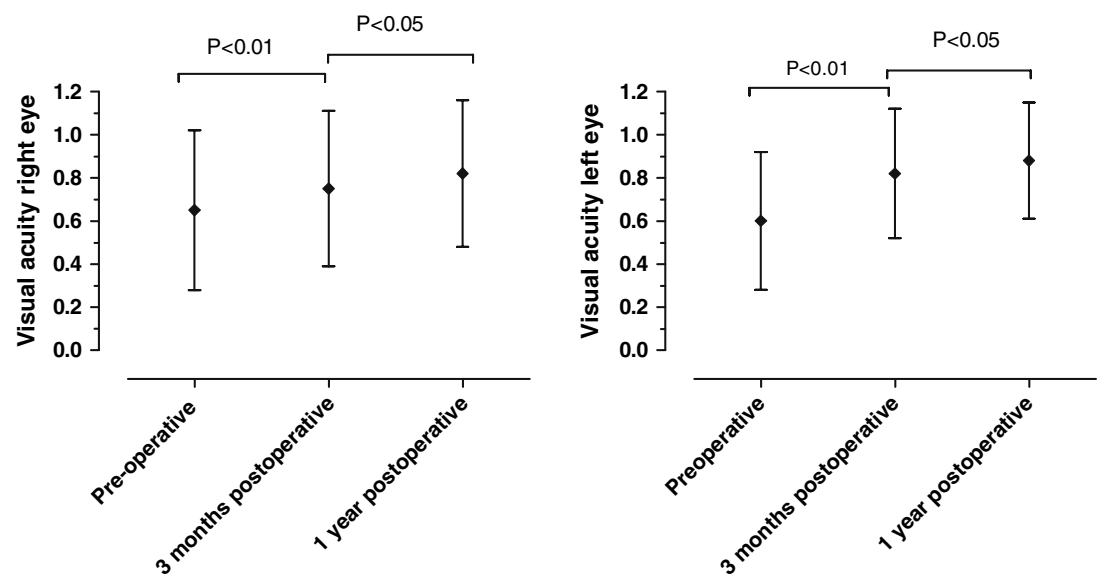

$0.75 \pm 0.36$ to $0.82 \pm 0.34(P<0.05)$ (right eye), and from $0.82 \pm 0.30$ to $0.88 \pm 0.27(P<0.05)$ (left eye).

\section{Discussion}

The main aims of surgery in non-functioning pituitary macroadenoma are restoration of visual acuity and visual field defects by decompression of the optic chiasm. Nonetheless, our data indicate that there is no necessity for immediate decompression, since postponement of surgery for several weeks did not result in deterioration of visual acuity. Moreover, in this series of 43 patients, we demonstrated a continuing improvement of visual acuity until 1 year after transsphenoidal surgery.

There is a significant correlation between the severity of visual loss prior to surgery and persisting visual field defects $[9,13,14]$. In our patients in whom visual acuity was assessed twice before surgery, no decrease of visual acuity was observed with a median time interval between two measurements of 4 weeks. This indicates that postponing surgery for 1 month does not negatively influence visual outcome, which is in line with the slow growth pattern of non-functioning adenomas [4]. Nonetheless, the delay of surgery should not unnecessarily be prolonged because a significant, inverse, correlation between visual outcome and the prolonged duration of symptoms has been reported [9]. Moreover, especially in patients with rapid loss of visual function or decreased visual acuity due to apoplexy, urgent surgical intervention is indicated.

The initial event in the pathogenesis of decreased visual function in pituitary macroadenomas is compression of the optic chiasm. Nerve compression leads to decreased conduction and to demyelination. In an experimental setting, the process of demyelination after nerve compression has been observed even after 2 days
[18, 19]. In case of continuous nerve compression remyelination can be observed after several weeks, although remyelinated fibers do not seem to reach normal thickness and organization structure, and complete demyelinated fibers co-exist [18, 19]. Re-myelinated fibers restore conduction, at least partially, even if the causative nerve lesion is still existing [20,21]. The improvement of visual dysfunction after surgical treatment is supposed to consist of two, or probably even three, phases [12]. There is an early phase, comprising the first hours and days after surgery. In this early fast phase, the improvement is caused by decompression of the visual pathways, leading to a restoration of signal conduction. Visual recovery has been demonstrated in the first days after surgical treatment [11, 12]. The second phase, i.e., delayed recovery, is pathophysiologically caused by restoration of axonal transport and remyelination, and based on remyelination of the optic nerve vessels. This phase of delayed recovery may last for several years $[12,13]$. A precise boundary between the end of the fast phase of recovery and the start of the delayed recovery seems to be artificial, because these two phases reflect different pathophysiological mechanisms, which may co-exist for a certain time-period. The contribution of the first phase of recovery might be larger, given the fact that more than $50 \%$ of eventual recovery takes place within the first 3 months after surgery [13].

It is already known that visual acuity improves in the first months after surgical treatment [6-10] and that the improvement of visual field defects is a continuing process for at least 1 year $[12,13]$. Kerrison et al. [12] showed progressive improvement of visual fields even more than 2 years after surgical decompression of the optic chiasm. However, they did not demonstrate this same pattern of recovery for visual acuity. This might be due to the relative small number of patients during prolonged follow-up. In the present study we 
demonstrate that also improvement of visual acuity continued 1 year after surgical treatment.

The clinical consequences of the delayed phase of recovery for both visual field defects and visual acuity are obvious. Follow-up of patients after surgical treatment for pituitary macroadenomas should include ophthalmologic assessment within several weeks after surgery, as well as subsequent assessments after one and 2 years, in order to estimate the final effect of surgery on visual function. Moreover, patients should be told that visual function can continue to improve, at least until 1 year after surgery. The relevance of these findings are obvious and is of importance to all patients, given the impact of a decreased visual acuity as an independent predictor for a decreased quality of life [22, 23]. Moreover, these data are essential in order to evaluate potential effects of recurrent pituitary adenomas on visual function.

Ten patients in our series received postoperative radiotherapy. However, it is unlikely that this treatment affected the results of our study. In a series reported by Gnanalingham et al. [13], in which $34 \%$ of all patients received postoperative radiotherapy, persistent improvement of visual field defects was documented even years after surgical therapy. In another series of 21 patients, 2 years after pituitary irradiation, there were no cases of radiation-induced visual field or visual acuity deterioration [24].

In conclusion, this study demonstrates that the improvement of visual acuity, after transsphenoidal treatment for non-functioning pituitary macroadenomas, consists of both an early and a delayed phase of recovery. After initial post-surgical recovery, a progressive delayed improvement of visual acuity at least until 1 year after transsphenoidal surgery, is likely to occur.

\section{References}

1. Feldkamp J, Santen R, Harms E, Aulich A, Modder U, Scherbaum WA (1999) Incidentally discovered pituitary lesions: high frequency of macroadenomas and hormonesecreting adenomas-results of a prospective study. Clin Endocrinol (Oxf) 51(1):109-113

2. McComb DJ, Ryan N, Horvath E, Kovacs K (1983) Subclinical adenomas of the human pituitary. New light on old problems. Arch Pathol Lab Med 107(9):488-491

3. Comtois R, Beauregard H, Somma M, Serri O, Aris-Jilwan N, Hardy J (1991) The clinical and endocrine outcome to trans-sphenoidal microsurgery of nonsecreting pituitary adenomas. Cancer 68(4):860-866

4. Dekkers OM, Pereira AM, Roelfsema F et al (2006) Observation alone after transsphenoidal surgery for nonfunctioning pituitary macroadenoma. J Clin Endocrinol Metab 91(5):1796-1801
5. Ebersold MJ, Quast LM, Laws ER Jr, Scheithauer B, Randall RV (1986) Long-term results in transsphenoidal removal of nonfunctioning pituitary adenomas. J Neurosurg 64(5):713-719

6. Powell M (1995) Recovery of vision following transsphenoidal surgery for pituitary adenomas. $\mathrm{Br} \mathrm{J}$ Neurosurg 9(3):367-373

7. Peter M, De Tribolet N (1995) Visual outcome after transsphenoidal surgery for pituitary adenomas. Br J Neurosurg 9(2):151-157

8. Zhang X, Fei Z, Zhang J et al (1999) Management of nonfunctioning pituitary adenomas with suprasellar extensions by transsphenoidal microsurgery. Surg Neurol 52(4):380-385

9. Cohen AR, Cooper PR, Kupersmith MJ, Flamm ES, Ransohoff J (1985) Visual recovery after transsphenoidal removal of pituitary adenomas. Neurosurgery 17(3):446-452

10. Trautmann JC, Laws ER Jr (1983) Visual status after transsphenoidal surgery at the Mayo Clinic, 1971-1982. Am J Ophthalmol 96(2):200-208

11. Jakobsson KE, Petruson B, Lindblom B (2002) Dynamics of visual improvement following chiasmal decompression. Quantitative pre- and postoperative observations. Acta Ophthalmol Scand 80(5):512-516

12. Kerrison JB, Lynn MJ, Baer CA, Newman SA, Biousse V, Newman NJ (2000) Stages of improvement in visual fields after pituitary tumor resection. Am $\mathbf{J}$ Ophthalmol 130(6):813-820

13. Gnanalingham KK, Bhattacharjee S, Pennington R, Ng J, Mendoza N (2005) The time course of visual field recovery following transphenoidal surgery for pituitary adenomas: predictive factors for a good outcome. J Neurol Neurosurg Psychiatry 76(3):415-419

14. Findlay G, McFadzean RM, Teasdale G (1983) Recovery of vision following treatment of pituitary tumours; application of a new system of assessment to patients treated by transsphenoidal operation. Acta Neurochir (Wien) 68(3-4):175-186

15. Ricci F, Cedrone C, Cerulli L (1998) Standardized measurement of visual acuity. Ophthalmic Epidemiol 5(1):41-53

16. Kniestedt C, Stamper RL (2003) Visual acuity, its measurement. Ophthalmol Clin North Am 16(2):155-170

17. Hardy J (1979) The transsphenoidal surgical approach to the pituitary. Hosp Pract 14(6):81-89

18. Clifford-Jones RE, Landon DN, McDonald WI (1980) Remyelination during optic nerve compression. J Neurol Sci 46(2):239-243

19. Clifford-Jones RE, McDonald WI, Landon DN (1985) Chronic optic nerve compression. An experimental study. Brain 108(Pt 1):241-262

20. Smith KJ, Blakemore WF, McDonald WI (1981) The restoration of conduction by central remyelination. Brain 104(2):383-404

21. Smith EJ, Blakemore WF, McDonald WI (1979) Central remyelination restores secure conduction. Nature 280(5721):395-396

22. Williams GP, Pathak-Ray V, Austin MW, Lloyd AP, Millington IM, Bennett A (2006) Quality of life and visual rehabilitation: an observational study of low vision in three general practices in West Glamorgan. Eye 2006

23. Klein R, Moss SE, Klein BE, Gutierrez $\mathrm{P}$, Mangione $\mathrm{CM}$ (2001) The NEI-VFQ-25 in people with long-term type 1 diabetes mellitus: the Wisconsin Epidemiologic Study of Diabetic Retinopathy. Arch Ophthalmol 119(5):733-740

24. Movsas B, Movsas TZ, Steinberg SM, Okunieff P (1995) Long-term visual changes following pituitary irradiation. Int J Radiat Oncol Biol Phys 33(3):599-605 